\title{
The effects of fentanyl, oxycodone, and butorphanol on gastrointestinal function in patients undergoing laparoscopic hysterectomy: a prospective, double-blind, randomized controlled trial
}

\author{
Minna Guo', Shijiang Liu², Jian Gao ${ }^{3}$, Chuanbao Han², Chun Yang ${ }^{2}$ and Cunming Liu²*
}

\begin{abstract}
Background: Perioperative opioid use is associated with postoperative bowel dysfunction, which causes longer hospital stay and higher healthcare costs. This study aimed to investigate the effect of the equivalent doses of fentanyl, oxycodone, and butorphanol on bowel function in patients undergoing laparoscopic hysterectomy.

Methods: In this randomized controlled trial, 135 patients undergoing laparoscopic hysterectomy received postoperative intravenous patient-controlled analgesia (IV-PCA) with fentanyl $8.3 \mu \mathrm{g} / \mathrm{kg}$, butorphanol $0.16 \mathrm{mg} / \mathrm{kg}$, and oxycodone $0.5 \mathrm{mg} / \mathrm{kg}(1: 20: 60)$, respectively. The primary outcome measure was the recovery of bowel function. We also evaluated and recorded the following nine indicators: pain score, sedation level, leukocyte count, percentage of neutrophils, plasma potassium levels, time to first ambulation, postoperative side effects, patients' satisfaction, and postoperative hospital length of stay.

Results: The mean time to flatus was significantly prolonged in Group B (45.2 \pm 11.6 h) compared with Group F $(33.1 \pm 11.2 \mathrm{~h}, P<0.001)$ and Group $\mathrm{O}(36.2 \pm 10.9 \mathrm{~h}, P=0.001)$. The incidence of somnolence and dizziness prove higher in Group B $(P<0.001)$. No statistical difference was observed in the mean time to tolerate oral diet, time to defecation, analgesic outcome, satisfaction score, time to first ambulation, and postoperative hospital length of stay.

Conclusions: Compared with fentanyl and oxycodone, butorphanol prolonged the recovery of bowel function with more severe somnolence and dizziness, suggesting that butorphanol is not well suitable for IV-PCA in patients undergoing laparoscopic hysterectomy.
\end{abstract}

Trial registration: ClinicalTrials.gov-NCT04295109. Date of registration: March, 2020.

Keywords: Postoperative gastrointestinal tract dysfunction, Opioid receptor, Analgesia

*Correspondence: cunmingliu@njmu.edu.cn

${ }^{2}$ Department of Anesthesiology and Perioperative Medicine, The First Affiliated Hospital of Nanjing Medical University, Nanjing, China

Full list of author information is available at the end of the article

\begin{abstract}
Background
Postoperative gastrointestinal tract dysfunction (PGID) is a frequent occurrence after abdominal surgery, which contributes to patient discomfort and increased healthcare costs [1]. Although the minimally invasive techniques bring less surgical trauma compared to open surgery, most of the patients experience post-laparoscopic pain
\end{abstract} permits use, sharing, adaptation, distribution and reproduction in any medium or format, as long as you give appropriate credit to the original author(s) and the source, provide a link to the Creative Commons licence, and indicate if changes were made. The images or other third party material in this article are included in the article's Creative Commons licence, unless indicated otherwise in a credit line to the material. If material is not included in the article's Creative Commons licence and your intended use is not permitted by statutory regulation or exceeds the permitted use, you will need to obtain permission directly from the copyright holder. To view a copy of this licence, visit http://creativecommons.org/licenses/by/4.0/. The Creative Commons Public Domain Dedication waiver (http://creativeco mmons.org/publicdomain/zero/1.0/) applies to the data made available in this article, unless otherwise stated in a credit line to the data. 
and call for opioid drugs [2,3]. However, consumption of opioid drugs may lead to PGID by activating opioid receptors, of which classical opioid receptors constitute muopioid receptors (MOR), delta-opioid receptors (DOR), and kappa-opioid receptors (KOR) $[4,5]$.

Most of the previous studies support that PGID is primarily mediated by MOR [4-6]. Therefore, some investigators tried MOR agonist-antagonist instead of pure MOR agonists to reduce the occurrence of PGID. Butorphanol, a mixed opioid receptor agonist-antagonist, has been shown to better lower the incidence of constipation than morphine, the pure MOR agonist [7]. Other investigators who compared pure MOR agonists with oxycodone, a semisynthetic opioid analgesic, which activates MOR and KOR, demonstrated that oxycodone showed a lower incidence of adverse complications than sufentanil $[8,9]$. However, these studies focused on two types of opioid receptor agonists and emphasized the differences between analgesic effects, taking nausea/vomiting, not bowel function, as postoperative gastrointestinal function evaluation criteria [7-9]. The effect of pure MOR agonists, multiple opioid receptor agonists, and MOR agonist-antagonist on PGID remains to be elucidated.

This study aimed to compare the effect of the equivalent doses of fentanyl (pure MOR agonists), oxycodone (multiple opioid receptor agonists), and butorphanol (MOR agonist-antagonist) on the recovery of bowel function in patients undergoing the laparoscopic hysterectomy, thereby providing a clinical reference for fundamental research.

\section{Methods}

This prospective, randomized and double-blind study was approved by the Institutional Review Board of the First Affiliated Hospital of Nanjing Medical University (IRB: 2019-SR-476), and conducted in compliance with local regulatory requirements, Good Clinical Practice (GCP), and the Declaration of Helsinki [10], and written informed consent was obtained from all subjects participating in the trial. The trial was registered prior to patient enrollment at clinicaltrials.gov (NCT04295109, Principal investigator: Cunming Liu, Date of registration: March $4,2020)$. This manuscript adheres to the applicable Consolidated Standards of Reporting Trials (CONSORT) guidelines.

\section{Patients}

We enrolled patients aged 40-65 years with the American Society of Anesthesiologists (ASA) physical status I-II undergoing laparoscopic hysterectomy. The exclusion criteria were as follows: history of gastrointestinal surgery or gastrointestinal disease (peptic ulcer disease, Crohn's disease, or ulcerative colitis, etc.); history of alcohol or opioid abuse; chronic use of opioids; allergy and contraindication to fentanyl, oxycodone or butorphanol, or any of their excipients; diabetes mellitus; severe cardiac/pulmonary/hepatic/renal dysfunction; psychiatric disease; pregnant or breastfeeding women; participants in other drug trials in the past three months. Also, participants were withdrawn for postoperative infection, bleeding and mechanical faults with intravenous patientcontrolled analgesia (IV-PCA) device.

\section{Anesthesia protocols}

Each patient was monitored using electrocardiography (EKG), pulse oximetry, capnography, temperature and Bispectral Index (BIS). Also, oxygen saturation $\left(\mathrm{SpO}_{2}\right)$, heart rate (HR) and mean blood pressure (MBP) were recorded every $5 \mathrm{~min}$.

After obtaining HR and MBP, anesthesia was induced with midazolam $0.05 \mathrm{mg} / \mathrm{kg}$, fentanyl $3 \mu \mathrm{g} / \mathrm{kg}$, etomidate $0.3 \mathrm{mg} / \mathrm{kg}$, dexamethasone $5-10 \mathrm{mg}$, and phencyclidine hydrochloride $0.5-1 \mathrm{mg}$, and cisatracurium $0.15 \mathrm{mg} / \mathrm{kg}$ as an adjunct to tracheal intubation. Fentanyl $6 \mu \mathrm{g} / \mathrm{kg}$ and flurbiprofen axetil $50 \mathrm{mg}$ were injected intravenously $10 \mathrm{~min}$ before skin incision. Propofol $\left(6-8 \mathrm{mg} \cdot \mathrm{kg}^{-1} \cdot \mathrm{h}^{-1}\right)$ and remifentanil $\left(0.05-0.2 \mu \mathrm{g} \cdot \mathrm{kg}^{-1} \cdot \mathrm{min}^{-1}\right)$ were given intraoperatively to titrate analgesia and keep HR and MBP within $20 \%$ of baseline values. Besides, cisatracurium $\left(0.1-0.2 \mathrm{mg} \cdot \mathrm{kg}^{-1} \cdot \mathrm{h}^{-1}\right)$ was used applied to maintain neuromuscular blockaded during surgery. End-tidal carbon dioxide concentration was controlled at $35-45 \mathrm{mmHg}(1 \mathrm{mmHg}=0.133 \mathrm{kPa})$ under $10-12 \mathrm{mmHg}$ pneumoperitoneum. BIS was maintained 40-60. If bradycardia ( $\mathrm{HR}<45$ beats $/ \mathrm{min})$ and continuous hypotension (MBP $<20 \%$ of the baseline values) persisted, additional fluid infusion, atropine, or ephedrine were administered. Patients were given intravenous granisetron $3 \mathrm{mg}$ near the completion of the procedure.

\section{PACU protocols}

After surgery, all patients were transferred to the postanesthesia care unit (PACU). Extubation was performed when the extubation criteria were met, and then the IVPCA device was used.

We used fentanyl, oxycodone or butorphanol in the IV-PCA device. Among them, we chose fentanyl group as the active-controlled group. Because fentanyl is one of the most widely used opioids for intravenous patientcontrolled analgesia (IV-PCA) and has fewer side effects [11-14]. Previous studies have shown a fentanyl-tooxycodone conversion ratio of 1:55-100 [15, 16]. However, when the fentanyl-oxycodone ratio is $\geq 1: 80$, most patients cannot tolerate the high incidence of nausea and vomit so analgesia therapy is always interrupted $[13,15]$. Therefore, the equivalent dose of fentanyl and 
oxycodone was 1: 60 in this study. Shin $S$ et al. have shown that a background infusion rate of fentanyl 0.12$0.67 \mu \mathrm{g} \cdot \mathrm{kg}^{-1} \cdot \mathrm{h}^{-1}$ is safe for IV-PCA with fewer side effects [17], so we used fentanyl $8.3 \mu \mathrm{g} / \mathrm{kg}$ and oxycodone $0.5 \mathrm{mg} / \mathrm{kg}$. The fentanyl-butorphanol ratio was $1: 20$ [18], so we used butorphanol $0.16 \mathrm{mg} / \mathrm{kg}$ for IV-PCA. In all groups, the parameters of the IV-PCA device remain the same: total volume of $100 \mathrm{~mL}$, background infusion of $2.0 \mathrm{~mL} / \mathrm{h}$, a bolus dose of $3.0 \mathrm{~mL}$, lock time $15 \mathrm{~min}$ and infusion time of $48 \mathrm{~h}$. And we provided all patients with flurbiprofen axetil $50 \mathrm{mg}$ for acute pain when they returned to the ward $2 \mathrm{~h}$ later.

\section{Randomization}

According to the result of the pre-experiment, 135 patients were randomized to three groups using a randomization list provided by The First Affiliated Hospital of Nanjing Medical University (computer-generated random number system), and the allocation concealment was performed using a sealed envelope by two independent researchers. To ensure blinding, an anesthesia nurse responsible for preparing IV-PCA in the PACU opened the sealed envelopes immediately after the procedure. The outcomes were recorded by another anesthetist who was blinded to the intervention. Unmasking did not occur until statistical analysis was completed.

\section{Outcome measures}

The primary outcome measure was the recovery of bowel function, including time to flatus, time to tolerance of solids and time to defecation. We also assessed the following nine indicators, including postoperative pain intensity (total opioid consumption, number of IVPCA boluses and 10-points visual analog scale (VAS) at $4,10,24$, and $48 \mathrm{~h}$ postoperatively), sedation level with Ramsay scale, the incidence of postoperative side effects, perioperative leukocyte count, percentage of neutrophils, plasma potassium levels, time to first ambulation, patients' satisfaction and postoperative hospital length of stay. If patients complained of pain, we recommended them to press the button of the IV-PCA device. Rescue analgesia (adjust the parameters of IV-PCA devices, and add the bolus dose) was given if the VAS score was more than 5 for $30 \mathrm{~min}$. If the patients were drowsy or had respiratory depression $\left(\mathrm{SpO}_{2}\right.$ was $<92 \%$ and respiration rate was $<10 \mathrm{breath} / \mathrm{min}$ ), we would try to wake them up and supply oxygen. If the patients didn't respond to oral commands appropriately and were persistently hypoxic, we discontinued the IV-PCA, gave reversal agents (naloxone), and excluded them from our experiment.

\section{Statistical Analysis}

Time to flatus was considered as the primary outcome. Based on the results of the pre-experiment (15 cases in each group, 45 cases in total), the mean time to flatus was $33.0 \mathrm{~h}, 35.3 \mathrm{~h}$, and $41.0 \mathrm{~h}$ for the three groups (Group F, Group O, and Group B), respectively.

And the standard deviations for the three groups were $8.9 \mathrm{~h}, 9.6 \mathrm{~h}$, and $6.8 \mathrm{~h}$, respectively. A sample size of 108 patients was found to be sufficient to detect a significant difference $(\alpha=5 \%)$ with a statistical power ( $\beta$-value) of 0.9. Considering a follow-up missed rate of approximately $20 \%$, we needed to enroll 135 patients. The sample size was calculated with the PASS 15.0 software (Stata Corp. LP, College Station, TX, USA).

The Shapiro-Wilk test was used to determine the normal distribution of the data, and parametric statistics were applied. Homogeneity of variance was verified by the Levene test. Normally distributed data were analyzed using one-way analysis of variance (ANOVA). Continuous variables were compared using the Kruskal-Wallis $\mathrm{H}$-test. Individual groups were compared using KruskalWallis $\mathrm{H}$-test. Repeated measurements were compared between groups using a general linear model including all time points. Simultaneously, Also, the $\chi^{2}$ test and Fisher's exact test were used to analyze categorical variables, a $P$-value of $<0.05$ was interpreted as statistically significant. SPSS 18.0 software (SPSS, Inc., Chicago, IL, USA) was used for all statistical analyses.

\section{Results}

From March to September 2020, a total of 160 patients underwent laparoscopic hysterectomy; 15 didn't meet the inclusion criteria and 10 declined to participate in the study. Therefore, 135 patients were first enrolled in the study, but 23 were lost to follow-up (13 were excluded due to mechanical faults of the IV-PCA pump and 10 patients were excluded for side effects). Thus, 112 patients were eventually incorporated into analysis, including 39 in group F, 36 in group $\mathrm{O}$ and 37 in group $\mathrm{F}$ (Fig. 1).

There was no significant difference in baseline patients' characteristics, operative data, anesthesia data, consumption of intraoperative fentanyl, leukocyte count, percentage of neutrophils, and preoperative plasma potassium levels (Table 1).

The primary outcome measure was the time to flatus (measured from the end of surgery), defined as the point at which patients noticed the first bowel sound or movement $[19,20]$. When noticing the first anal exhaust, patients were informed to record it or to notify nurses for judgement to ensure no data were missed. The mean 


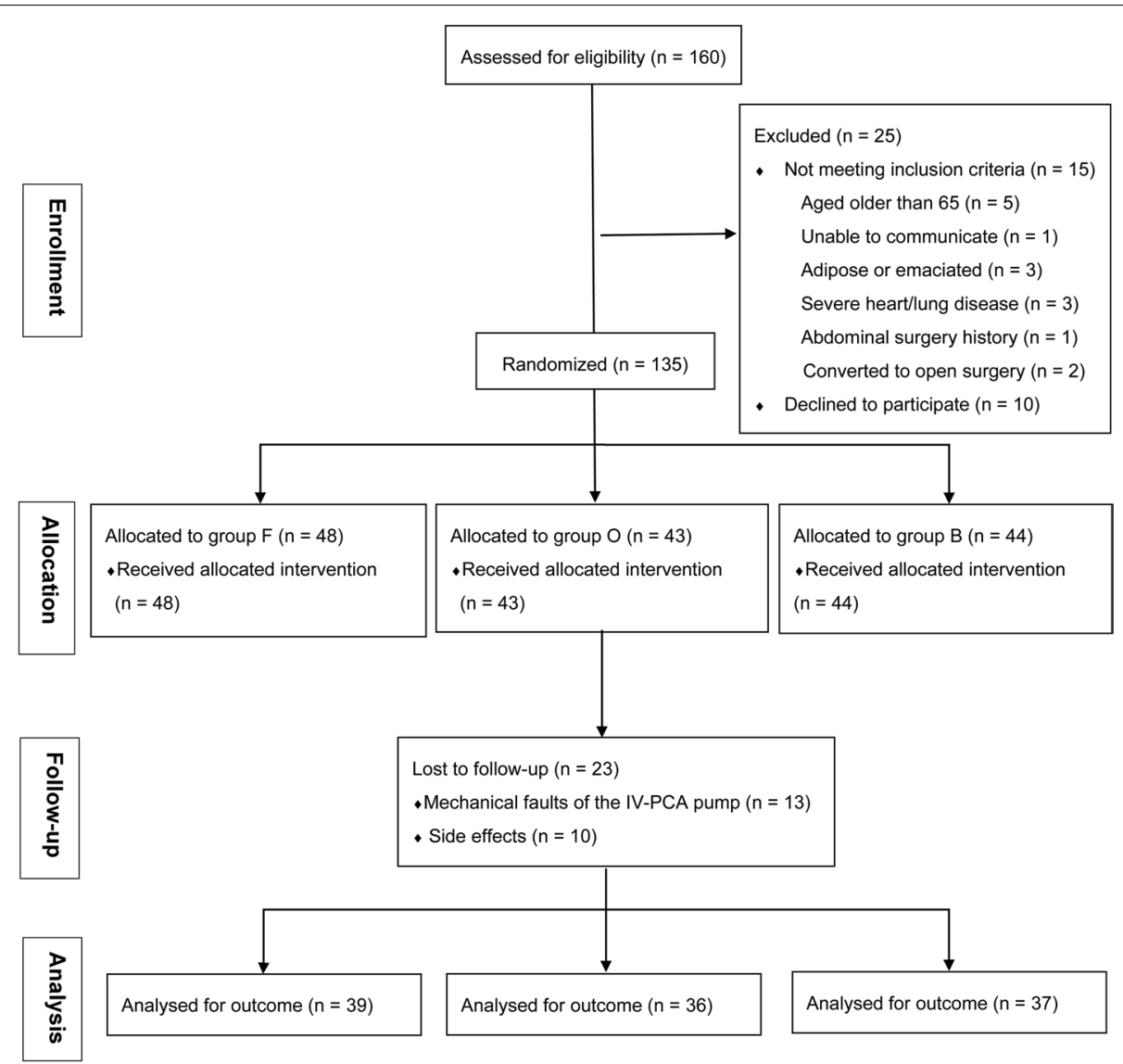

Fig. 1 Consort flow diagram. Abbreviations: $B=$ butorphanol; CONSORT = Consolidated Standards of Reporting Trials; $F=$ fentanyl; IV-PCA = intravenous patient-controlled analgesia; $\mathrm{O}=$ oxycodone.

time to flatus was significantly prolonged in Group B $(45.2 \pm 11.6 \mathrm{~h})$ compared with Group F $(33.1 \pm 11.2 \mathrm{~h}$, $P<0.001)$ and Group O $(36.2 \pm 10.9 \mathrm{~h}, P=0.001)$.

The secondary outcomes were time to the first defecation, and time to tolerance of solids, which was defined as the patients tolerating solid food (any food requiring chewing) without vomiting or experiencing significant nausea within $4 \mathrm{~h}$ [19]. The mean time to tolerate oral diet was $2.9 \pm 1.1 \mathrm{~d}, 2.9 \pm 0.6 \mathrm{~d}$, and $3.0 \pm 0.8 \mathrm{~d}$ for Group F, Group O, and Group B, respectively. The mean time to defecation of the three groups (Group F, Group O, and Group B) prove $4.3 \pm 1.7 \mathrm{~d}, 4.8 \pm 1.5 \mathrm{~d}$, and $4.7 \pm 1.5 \mathrm{~d}$, respectively. There was no significant difference in the meantime to tolerate oral diet and time to achieve defecation (Fig. 2).

Table 2 displays the analgesic outcome and the incidence of significant postoperative side effects. There was no difference in VAS, opioid consumption, and the number of IV-PCA boluses at 4, 10, 24, and $48 \mathrm{~h}$ after surgery, respectively. Ramsay scores in Group B were higher than those in Group F and Group O at 4, 10, 24, and $48 \mathrm{~h}$ after surgery, respectively $(P<0.001)$. Patients in Group
B experienced significantly more severe somnolence $(P<0.001)$ compared to Group O and Group F. The three groups witnessed a similar incidence of nausea, vomiting, and bradycardia. None of the patients included in this study experienced respiratory depression or pruritus. Overall, no difference was observed in the satisfaction score, time to first ambulation, and postoperative hospital length of stay (Table 3 ).

\section{Discussion}

We found that (1) fentanyl, a pure MOR agonist, had less effect on bowel function in laparoscopic hysterectomy patients; (2) oxycodone, MOR and KOR agonist showed an equivalent effect on bowel function compared to fentanyl; (3) butorphanol, a mixed opioid receptor agonist-antagonist, prolonged the recovery time of bowel function and increased the incidence of postoperative somnolence and dizziness.

Perioperative use of opioids for acute pain might cause PGID, whose clinical manifestations comprise abdominal distension, pain, nausea, vomiting, and even ileus [1]. Such symptoms considerably impair patients' 
Table 1 Patients' characteristics and other factor

\begin{tabular}{|c|c|c|c|}
\hline & Group F ( $n=39)$ & Group O $(n=36)$ & Group B $(n=37)$ \\
\hline Age (y) & $52.5 \pm 6.6$ & $51.4 \pm 6.7$ & $51.4 \pm 6.9$ \\
\hline Height (cm) & $159.7 \pm 4.6$ & $159.1 \pm 4.0$ & $160.2 \pm 4.2$ \\
\hline Weight (kg) & $60(55-72)$ & $60(60-68)$ & $60(56-74)$ \\
\hline BMI $\left(\mathrm{kg} / \mathrm{m}^{2}\right)$ & $24.7(22.1-25.8)$ & $24.9(23.4-26.5)$ & $23.4(22-25)$ \\
\hline \multicolumn{4}{|l|}{ ASA status } \\
\hline I [n (\%)] & $4(10.3)$ & $3(8.3)$ & $2(5.4)$ \\
\hline II [n (\%)] & $35(89.7)$ & $33(91.7)$ & $35(94.6)$ \\
\hline \multicolumn{4}{|l|}{ Diagnosis } \\
\hline Cancer [n (\%)] & $18(46.2)$ & $15(41.7)$ & $18(48.6)$ \\
\hline $\mathrm{CIN}[\mathrm{n}(\%)]$ & $12(30.8)$ & $14(38.9)$ & $9(24.4)$ \\
\hline Uterine fibroids [n (\%)] & $6(15.3)$ & $3(8.3)$ & $7(18.9)$ \\
\hline Adenomyosis [n (\%)] & $3(7.7)$ & $4(11.1)$ & $3(8.1)$ \\
\hline Duration of surgery (min) & $132(100-193)$ & $125(90-159)$ & $115(90-140)$ \\
\hline Duration of anesthesia (min) & $162(120-235)$ & 153(121-185) & $140(112-165)$ \\
\hline Consumption of fentanyl (mg) & $0.55(0.50-0.65)$ & $0.60(0.50-0.60)$ & $0.55(0.50-0.60)$ \\
\hline Total fluid (mL) & $2100(1600-2675)$ & $2100(1975-2500)$ & $2000(1600-2600)$ \\
\hline Total loss (mL) & $300(200-507)$ & $250(150-400)$ & $250(150-388)$ \\
\hline Leukocyte count $\left({ }^{*} 10^{9} / \mathrm{L}\right)$ & $5.7(4.7-7.3)$ & $5.3(4.7-6.6)$ & $5.2(4.4-6)$ \\
\hline Percentage of neutrophils (\%) & $56.3(51.6-64.2)$ & $56.3(51.4-64.5)$ & $56.5(52.3-60.1)$ \\
\hline Potassium (mmol/L) & $3.8(3.5-4.0)$ & $3.8(3.5-4.0)$ & $3.8(3.6-4.0)$ \\
\hline
\end{tabular}

Table legends: Normally distributed data are presented as mean \pm SD, which were analyzed using ANOVA; non-normal data are presented as median (range), which were analyzed using Kruskal-Wallis $\mathrm{H}$-test; categorical variables are presented as count (\%), which were analyzed using the $X^{2}$ test and Fisher's exact test

Abbreviations: ASA American Society of Anesthesiologists, ANOVA one-way analysis of variance, BMI body mass index, $B$ butorphanol, CIN cervical intraepithelial neoplasia, $F$ fentanyl, $O$ oxycodone, $S D$ standard deviation
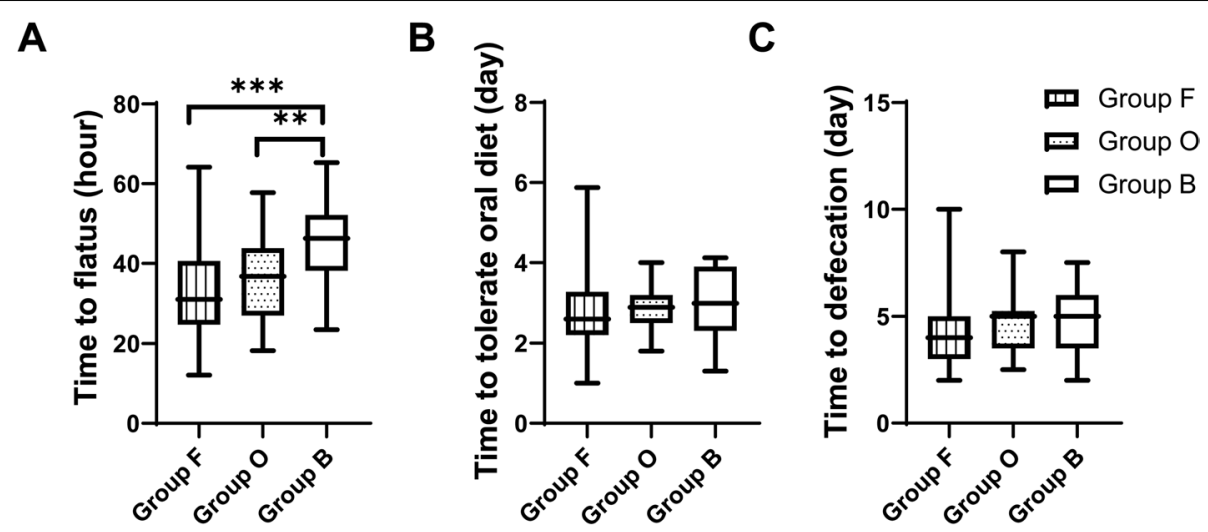

Fig. 2 The recovery of bowel function. A Box plot comparing the mean time to flatus (measured from surgery). The mean time to flatus significantly longer in the group B $\left({ }^{* * *} P<0.001\right.$, Group F versus Group B, ${ }^{* *} P<0.01$, Group O versus Group B, one-way ANOVA, followed by Bonferroni's post hoc test). B. Box plot comparing mean time to tolerate oral diet (measured from surgery). $\mathbf{C}$ Box plot comparing the time to defecation (measured from surgery). Abbreviations: ANOVA = one-way analysis of variance; $\mathrm{B}=$ butorphanol; $\mathrm{F}=$ fentanyl; $\mathrm{O}=$ oxycodone

recovery after surgery [1]. Currently, many comparisons of analgesic effects were made between opioids, but few studies were conducted on the effects of different opioids on bowel function $[7,13,21,22]$. In this study, we explored the effect of the equivalent doses of pure MOR agonists, multiple opioid receptor agonists, and MOR agonist-antagonist on the recovery of bowel function in patients undergoing laparoscopic hysterectomy.

Our result suggested pure MOR agonists had less effect on bowel function. This is in disagreement with previous studies documenting that pure MOR agonists prolonged the recovery of bowel function than other opioid 
Table 2 Analgesic outcome and postoperative side effects

\begin{tabular}{|c|c|c|c|c|}
\hline & Group F $(n=39)$ & Group O $(n=36)$ & Group B $(n=37)$ & $P$-value \\
\hline Postoperative VAS pain scores & & & & 0.517 \\
\hline $4 \mathrm{~h}$ & $1.5(1-3)$ & $2(1-4)$ & $2(1.5-3)$ & \\
\hline $12 \mathrm{~h}$ & $2(1-2.5)$ & $2(1-3)$ & $2(1.5-3)$ & \\
\hline $24 \mathrm{~h}$ & $2(1-2.5)$ & $2(1-3)$ & $2(1-3)$ & \\
\hline $48 \mathrm{~h}$ & $0(0-0.5)$ & $0(0-1)$ & $0.5(0-1)$ & \\
\hline Total opioid consumption (mg) & & & & 0.155 \\
\hline $4 \mathrm{~h}$ & $7.8(7.2-8)$ & $7.9(7.5-9.2)$ & $7.5(7.1-7.8)$ & \\
\hline $12 \mathrm{~h}$ & $30(27.7-30)$ & $31.3(29.3-33)$ & $30(28.4-31)$ & \\
\hline $24 \mathrm{~h}$ & $45(43-50)$ & $47(43.9-50)$ & $45(42.5-47)$ & \\
\hline $48 \mathrm{~h}$ & $90(85.3-100)$ & $92(87.8-96)$ & $90(84-93)$ & \\
\hline Number of IV-PCA boluses (times) & & & & 0.167 \\
\hline $4 \mathrm{~h}$ & $0(0-0)$ & $0(0-1)$ & $0(0-0)$ & \\
\hline $12 \mathrm{~h}$ & $0(0-0)$ & $0(0-1)$ & $0(0-0)$ & \\
\hline $24 \mathrm{~h}$ & $0(0-0)$ & $0(0-1)$ & $0(0-0)$ & \\
\hline $48 \mathrm{~h}$ & $0(0-1)$ & $0(0-1)$ & $0(0-0)$ & \\
\hline Postoperative Ramsay scores & & & & $<0.001$ \\
\hline $4 \mathrm{~h}$ & $2(2-2)$ & $2(2-2)$ & $3(2-4)$ & \\
\hline $12 \mathrm{~h}$ & $2(2-3)$ & $2(2-2)$ & $3(2-4)$ & \\
\hline $24 \mathrm{~h}$ & $2(2-2)$ & $2(2-2)$ & $2(2-3)$ & \\
\hline $48 \mathrm{~h}$ & $2(2-2)$ & $2(2-2)$ & $2(2-3)$ & \\
\hline \multicolumn{5}{|l|}{ Postoperative side effects } \\
\hline Somnolence [n (\%)] & $1(2.6)$ & $0(0)$ & $10(27)$ & $<0.001$ \\
\hline Dizziness [n (\%)] & $0(0)$ & $2(5.6)$ & $5(13.5)$ & 0.03 \\
\hline Nausea [n (\%)] & $4(10.3)$ & $3(8.3)$ & $8(21.6)$ & 0.27 \\
\hline Vomiting [n (\%)] & $0(0)$ & $3(8.3)$ & $2(5.4)$ & 0.16 \\
\hline Bradycardia [n (\%)] & $0(0)$ & $0(0)$ & $1(2.7)$ & 0.65 \\
\hline
\end{tabular}

Table legends: Non-normal data are presented as median (range), which were analyzed using Kruskal-Wallis H-test; repeated measurements were compared between groups using a general linear model including all time-points; categorical variables are presented as count (\%), which were analyzed using the $x^{2}$ test and Fisher's exact test

Abbreviations: $B$ butorphanol, $F$ fentanyl; IV-PCA intravenous patient-controlled analgesia, $O$ oxycodone, VAS visual analog scale

Table 3 The overall postoperative recovery measurement

\begin{tabular}{lllll}
\hline & Group F $(\boldsymbol{n}=\mathbf{3 9})$ & Group O $(\boldsymbol{n}=\mathbf{3 6})$ & Group B $(\boldsymbol{n}=\mathbf{3 7})$ & $\boldsymbol{P}$-value \\
\hline Leukocyte count $\left.{ }^{*} 10^{9} / \mathrm{L}\right)$ & $9.3(7.7-11.9)$ & $9.0(7.4-12)$ & $9.3(7.6-11)$ & $80.9(72.2-83.5)$ \\
Percentage of neutrophils (\%) & $79.5(67.1-83.5)$ & $79.9(68.9-84.5)$ & $3.8(3.6-4.0)$ & 0.80 \\
Potassium (mmol/L) & $3.8(3.6-4.0)$ & $3.8(3.6-4.1)$ & $10(9-10)$ & 0.60 \\
Satisfaction & $10(10-10)$ & $10(9.6-10)$ & $17.2(15.6-19.5)$ & 0.08 \\
Time to first ambulation (h) & $17.3(15.4-19.3)$ & $17.3(15.9-19.6)$ & $6(5-7)$ & 0.54 \\
Hospital length of stay (d) & $6(5-8)$ & $6(5-7)$ & & 0.45 \\
\hline
\end{tabular}

Table legends: Non-normal data are presented as median (range), which were analyzed using Kruskal-Wallis $\mathrm{H}$-test

Abbreviations: $B$ butorphanol, $F$ fentanyl, $O$ oxycodone

receptor agonists [7-9, 22]. Several reasons can explain these findings. First, we took fentanyl as the pure MOR agonist, because fentanyl enjoys fewer peripheral side effects than morphine for its lipophilic [23, 24]. Second, the equivalent dose of fentanyl and oxycodone was lower than in previous studies [22, 25]. With the oxycodone dose reduced, the incidence of postoperative nausea and vomiting remains lower. In this sense, intravenous dexamethasone and phencyclidine hydrochloride during anesthesia induction might curtail postoperative gastrointestinal side effects [26, 27]. By reducing the incidence of side effects, we improved patient compliance and 
reduced the rate of loss to follow-up. Third, total intravenous anesthesia was administered throughout the surgery. So, the effect of inhalation anesthesia on gastrointestinal function was ruled out $[7,28]$. Forth, we found that fentanyl, oxycodone, and butorphanol allowed for equivalent analgesia. This is in agreement with previous studies. Nevertheless, we used a lower equivalent dose of fentanyl and oxycodone (1: 60) than in previous studies [22, 25]. Considering the high price of oxycodone, our analgesic regimen is reasonable to reduce the total costs related to pain management in patients. In addition, butorphanol significantly induced more severe somnolence via interaction with KOR, which is consistent with previous studies $[29,30]$. In particular, the KOR agonist-related side effects were significantly greater in women than men [31,32]. Thus, patients treated with butorphanol were reluctant to engage in postoperative physical activities, which would prolong the recovery of bowel function [33].

We showed that butorphanol, the MOR opioid receptor agonist-antagonist, has no advantage in the occurrence of PGID compared with fentanyl, the pure MOR agonists. We, therefore, speculated that PGID is not only caused by MOR but also by other opioid receptors. Thus, further work on the pharmacological mechanism of opioid receptors in enteric neurons systems is needed. And to avoid PGID, we need multimodal anesthesia and analgesia based on opioid-free or opioid-sparing regimens to reduce perioperative opioid consumption $[34,35]$.

Some limitations also stand out in the present study: (1) butorphanol might have higher efficacy for KOR in females than in males [31, 32]. This study had limited samples and was female-only; therefore, further studies are needed in a large cohort of male and female individuals; (2) we gave a large dose of fentanyl intraoperatively in all three groups, and the elimination/clearance half-life of fentanyl was 2-4 h [36], so the effect of high-dose fentanyl on postoperative bowel function may be disruptive. Thus, further studies may use multimodal analgesia protocols to limit the consumption of perioperative opioid drugs; (3) postoperative gastrointestinal function evaluation criteria are subjective. Although "time to flatus" was adopted by many clinical trials $[19,37]$, there is still a need for systematic and objective criteria for evaluating gastrointestinal function.

\section{Conclusion}

This study showed butorphanol prolonged the recovery of bowel function with more severe somnolence and dizziness, while fentanyl, a pure MOR agonist, interfered much less with bowel function. This study indicated butorphanol, a mixed opioid receptor agonist-antagonist, is not well suitable for IV-PCA in patients undergoing laparoscopic hysterectomy.

\section{Abbreviations}

ASA: American Society of Anesthesiologists; ANOVA: One-way analysis of variance; BIS: Bispectral Index; CONSORT: Consolidated Standards of Reporting Trials; DOR: Delta-opioid receptors; EKG: Electrocardiography; HR: Heart rate; IV-PCA: Intravenous patient-controlled analgesia; KOR: Kappa-opioid receptors; MOR: Mu-opioid receptors; MBP: Mean blood pressure; PGID: Postoperative gastrointestinal tract dysfunction; PACU: Post-anesthesia care unit; $\mathrm{SpO}_{2}$ : Oxygen saturation; VAS: Visual analogue scale.

\section{Acknowledgements}

Not applicable

\section{Authors' contributions}

Study design: CML, CY; Data collection: MNG, CBH; Data analysis: JG, SJL; Manuscript writing: MNG; all authors have read and agreed to submit the manuscript.

Funding

Not applicable

\section{Availability of data and materials}

The data are not available for public access because of patient privacy concerns, but are available from the corresponding author on reasonable request.

\section{Declarations}

Ethics approval and consent to participate

The study was approved by the Institutional Review Board of the First Affiliated Hospital of Nanjing Medical University (IRB: 2019-SR-476), and written informed consent was obtained from all subjects participating in the trial.

Consent for publication

Not applicable.

\section{Competing interests}

The authors declare that they have no competing interests.

\section{Author details}

${ }^{1}$ Faculty of Anesthesiology, Changhai Hospital, Naval Medical University, Shanghai, China. ${ }^{2}$ Department of Anesthesiology and Perioperative Medicine, The First Affiliated Hospital of Nanjing Medical University, Nanjing, China. ${ }^{3}$ School of Public Health, Shanxi Medical University, Taiyuan, China.

Received: 23 June 2021 Accepted: 17 February 2022

Published online: 24 February 2022

\section{References}

1. Mythen MG. Postoperative gastrointestinal tract dysfunction. Anesth Analg. 2005;100(1):196-204.

2. Zeeni C, Chamsy D, Khalil A, Abu Musa A, Al Hassanieh M, Shebbo F, Nassif J. Effect of postoperative Trendelenburg position on shoulder pain after gynecological laparoscopic procedures: a randomized clinical trial. BMC Anesthesiol. 2020;20(1):27.

3. Kongwattanakul K, Khampitak K. Comparison of laparoscopically assisted vaginal hysterectomy and abdominal hysterectomy: a randomized controlled trial. J Minim Invasive Gynecol. 2012;19(1):89-94.

4. Hughes PA, Costello SP, Bryant RV, Andrews JM. Opioidergic effects on enteric and sensory nerves in the lower GI tract: basic mechanisms and clinical implications. Am J Physiol Gastrointest Liver Physiol. 2016:311(3):G501-513.

5. Galligan JJ, Sternini C. Insights into the Role of Opioid Receptors in the GI Tract: Experimental Evidence and Therapeutic Relevance. Handb Exp Pharmacol. 2017;239:363-78. 
6. de Boer HD, Detriche O, Forget P: Opioid-related side effects: Postoperative ileus, urinary retention, nausea and vomiting, and shivering. A review of the literature. Best Pract Res Clin Anaesthesiol 2017, 31(4):499-504.

7. Wang F, Shen X, Liu Y, Xu S, Guo X. Continuous infusion of butorphanol combined with intravenous morphine patient-controlled analgesia after total abdominal hysterectomy: a randomized, double-blind controlled trial. Eur J Anaesthesiol. 2009;26(1):28-34.

8. Tao B, Liu K, Wang D, Ding M, Zhao P. Effect of Intravenous Oxycodone Versus Sufentanil on the Incidence of Postoperative Nausea and Vomiting in Patients Undergoing Gynecological Laparoscopic Surgery. J Clin Pharmacol. 2019;59(8):1144-50.

9. Han L, Su Y, Xiong H, Niu X, Dang S, Du K, Li Q, Liu J, Zhang P, Li S. Oxycodone versus sufentanil in adult patient-controlled intravenous analgesia after abdominal surgery: A prospective randomized double-blinded multiple-center clinical trial. Medicine (Baltimore). 2018;97(31):e11552.

10. World Medical A. World Medical Association Declaration of Helsinki: ethical principles for medical research involving human subjects. JAMA. 2013;310(20):2191-4.

11. Vallejo MC, Edwards RP, Shannon KT, Kaul B, Finegold H, Morrison HL, Ramanathan S. Improved bowel function after gynecological surgery with epidural bupivacaine-fentanyl than bupivacaine-morphine infusion. Can J Anaesth. 2000;47(5):406-11.

12. Russo A, Grieco DL, Bevilacqua F, Anzellotti GM, Scarano A, Scambia G, Costantini B, Marana E. Continuous intravenous analgesia with fentanyl or morphine after gynecological surgery: a cohort study. J Anesth. 2017;31(1):51-7.

13. Park JH, Lee C, Shin Y, An JH, Ban JS, Lee JH. Comparison of oxycodone and fentanyl for postoperative patient-controlled analgesia after laparoscopic gynecological surgery. Korean J Anesthesiol. 2015;68(2):153-8.

14. Asgari Z, Tavoli Z, Hosseini R, Nataj M, Tabatabaei F, Dehghanizadeh F, Haji-Amoo-Assar H, Sepidarkish M, Montazeri A. A Comparative Study between Transcutaneous Electrical Nerve Stimulation and Fentanyl to Relieve Shoulder Pain during Laparoscopic Gynecologic Surgery under Spinal Anesthesia: A Randomized Clinical Trail. Pain Res Manag. 2018:2018:9715142.

15. Raff M, Belbachir A, El-Tallawy S, Ho KY, Nagtalon E, Salti A, Seo JH, Tantri AR, Wang $H$, Wang T, et al. Intravenous Oxycodone Versus Other Intravenous Strong Opioids for Acute Postoperative Pain Control: A Systematic Review of Randomized Controlled Trials. Pain Ther. 2019;8(1):19-39.

16. Koh JC, Kong HJ, Kim MH, Hong JH, Seong H, Kim NY, Bai SJ. Comparison of Analgesic and Adverse Effects of Oxycodone- and Fentanyl-Based Patient-Controlled Analgesia in Patients Undergoing Robot-Assisted Laparoscopic Gastrectomy Using a 55:1 Potency Ratio of Oxycodone to Fentanyl: A Retrospective Study. J Pain Res. 2020;13:2197-204.

17. Shin S, Min KT, Shin YS, Joo HM, Yoo YC. Finding the "ideal" regimen for fentanyl-based intravenous patient-controlled analgesia: how to give and what to mix? Yonsei Med J. 2014;55(3):800-6.

18. Pachter IJ, Evens RP. Butorphanol. Drug Alcohol Depend. 1985;14(3-4):325-38.

19. Ozdemir IA, Comba C, Demirayak G, Gulseren V, Erdogan SV, Aslanova F, Afsar S, Gungorduk K. Impact of pre-operative walking on post-operative bowel function in patients with gynecologic cancer. Int J Gynecol Cancer. 2019:29(8):1311-6.

20. Gero D, Gie O, Hubner M, Demartines N, Hahnloser D. Postoperative ileus: in search of an international consensus on definition, diagnosis, and treatment. Langenbecks Arch Surg. 2017:402(1):149-58.

21. Jung KW, Kang HW, Park CH, Choi BH, Bang JY, Lee SH, Lee EK, Choi BM, Noh GJ. Comparison of the analgesic effect of patient-controlled oxycodone and fentanyl for pain management in patients undergoing colorectal surgery. Clin Exp Pharmacol Physiol. 2016;43(8):745-52.

22. Hwang BY, Kwon JY, Kim E, Lee DW, Kim TK, Kim HK. Oxycodone vs. fentanyl patient-controlled analgesia after laparoscopic cholecystectomy. Int J Med Sci. 2014;11(7):658-62.

23. Holzer P, Ahmedzai SH, Niederle N, Leyendecker P, Hopp M, Bosse B, Spohr I, Reimer K. Opioid-induced bowel dysfunction in cancer-related pain: causes, consequences, and a novel approach for its management. J Opioid Manag. 2009;5(3):145-51.

24. Mori T, Shibasaki Y, Matsumoto K, Shibasaki M, Hasegawa M, Wang E, Masukawa D, Yoshizawa K, Horie S, Suzuki T. Mechanisms that underlie muopioid receptor agonist-induced constipation: differential involvement of mu-opioid receptor sites and responsible regions. J Pharmacol Exp Ther. 2013;347(1):91-9.

25. Kim NS, Lee JS, Park SY, Ryu A, Chun HR, Chung HS, Kang KS, Chung JH, Jung KT, Mun ST. Oxycodone versus fentanyl for intravenous patientcontrolled analgesia after laparoscopic supracervical hysterectomy: A prospective, randomized, double-blind study. Medicine (Baltimore). 2017;96(10):e6286.

26. Sun YJ, Song DD, Diao YG, Zhou J, Zhang TZ. Penehyclidine hydrochloride preserves the intestinal barrier function in patients undergoing cardiopulmonary bypass. J Thorac Cardiovasc Surg. 2013;146(1):179-85.

27. Collaborators DT, West Midlands Research C. Dexamethasone versus standard treatment for postoperative nausea and vomiting in gastrointestinal surgery randomised controlled trial (DREAMS Trial). BMJ. 2017;357:j1455

28. Aftab H, Fagerland MW, Gondal G, Ghanima W, Olsen MK, Nordby T. Gastric sleeve resection as day-case surgery: what affects the discharge time? Surg Obes Relat Dis. 2019;15(12):2018-24.

29. Dogra S, Yadav PN. Biased agonism at kappa opioid receptors: Implication in pain and mood disorders. Eur J Pharmacol. 2015;763(Pt B):184-90.

30. Jose DE, Ganapathi P, Anish Sharma NG, Shankaranarayana P, Aiyappa DS, Nazim M. Postoperative pain relief with epidural buprenorphine versus epidural butorphanol in laparoscopic hysterectomies: A comparative study. Anesth Essays Res. 2016;10(1):82-7.

31. Sibille KT, Kindler LL, Glover TL, Gonzalez RD, Staud R, Riley JL 3rd, Fillingim RB. Individual differences in morphine and butorphanol analgesia: a laboratory pain study. Pain Med. 2011;12(7):1076-85.

32 Craft RM, McNiel DM. Agonist/antagonist properties of nalbuphine, butorphanol and (-)-pentazocine in male vs female rats. Pharmacol Biochem Behav. 2003;75(1):235-45.

33. Wang G, Jiang ZW, Xu J, Gong JF, Bao Y, Xie LF, Li JS. Fast-track rehabilitation program vs conventional care after colorectal resection: a randomized clinical trial. World J Gastroenterol. 2011;17(5):671-6.

34. Echeverria-Villalobos M, Stoicea N, Todeschini AB, Fiorda-Diaz J, Uribe AA, Weaver T, Bergese SD. Enhanced Recovery After Surgery (ERAS): A Perspective Review of Postoperative Pain Management Under ERAS Pathways and Its Role on Opioid Crisis in the United States. Clin J Pain. 2020;36(3):219-26.

35. Ghimire A, Subedi A, Bhattarai B, Sah BP. The effect of intraoperative lidocaine infusion on opioid consumption and pain after totally extraperitoneal laparoscopic inguinal hernioplasty: a randomized controlled trial. BMC Anesthesiol. 2020;20(1):137.

36. Comer SD, Cahill CM. Fentanyl: Receptor pharmacology, abuse potential, and implications for treatment. Neurosci Biobehav Rev. 2019;106:49-57.

37. Gungorduk K, Ozdemir IA, Gungorduk O, Gulseren V, Gokcu M, Sanci $M$. Effects of coffee consumption on gut recovery after surgery of gynecological cancer patients a randomized controlled trial. Am J Obstet Gynecol. 2017;216(2):e141-5.

\section{Publisher's Note}

Springer Nature remains neutral with regard to jurisdictional claims in published maps and institutional affiliations.

Ready to submit your research? Choose BMC and benefit from:

- fast, convenient online submission

- thorough peer review by experienced researchers in your field

- rapid publication on acceptance

- support for research data, including large and complex data types

- gold Open Access which fosters wider collaboration and increased citations

- maximum visibility for your research: over 100M website views per year

At BMC, research is always in progress.

Learn more biomedcentral.com/submissions 